\title{
DAMAGE RATIOS FOR PLANT, EQUIPMENT AND STOCK IN THE 1987 EDGECUMBE, NEW ZEALAND EARTHQUAKE
}

\author{
D.J. Dowrick' and D.A. Rhoades ${ }^{2}$
}

\begin{abstract}
This paper describes an analysis of damage costs to commercial and industrial equipment (plant) and stock in the $M_{w}=6.6$ Edgecumbe, New Zealand, earthquake of 2 March 1987. The damage costs were converted to damage ratios by dividing by the value of the relevant property parcel. The mean value and statistical distribution of damage ratios were found for various classes of equipment and stock in the MM7 and MM9 intensity Zones. The lognormal distribution generally fitted the data well.

Equipment and stock are much more variable in nature than modern buildings, and in large part are not designed for earthquakes. In this study they were analysed in subsets formed by classification according to Use (i.e. shops, offices, halls, residential or industrial) and Vulnerability (i.e. Robust, Medium or Fragile). These classifications provided useful insights into variations in the damage ratio. The overall mean damage ratio, $\mathrm{D}_{\mathrm{rm}}$, for stock was considerably higher than for equipment, even though $\mathrm{D}_{\mathrm{rm}}$ for Fragile equipment was higher than $\mathrm{D}_{\mathrm{rm}}$ for Fragile stock. This occurred because the proportion of stock that was Fragile was much larger than the corresponding proportion of equipment. The proportional difference in damage levels between Fragile and Robust property was greater at intensity MM7 than at MM9. This is consistent with the definitions of the Modified Mercalli scale. A comparison of the damage to equipment and buildings showed that, at MM9, the mean and distribution of damage ratios for Medium vulnerability equipment are similar to those for the associated single storey, post-code $(1935+)$ commercial and industrial buildings.
\end{abstract}

\section{INTRODUCTION}

The $M_{w}=6.6$ Edgecumbe earthquake of 2 March 1987 was centred in the north-east of New Zealand in the Bay of Plenty. Our present region of interest extends from the centre to the isoseismal for Modified Mercalli intensity VI (MM6), as shown on the isoseismal map (Figure 1) used here and in our previous studies [Dowrick, 1991; Dowrick and Rhoades, 1991, 1993].

The amount of damage that will occur in a future earthquake of any given size and location is difficult to forecast accurately partly because of the lack of detailed damage data from past earthquakes, both in New Zealand and elsewhere. The Edgecumbe earthquake caused appreciable damage and had strong ground shaking with intensity up to MM9, and provided an excellent and rare opportunity to obtain detailed damage data for a broad sample of the New Zealand built environment. Studies of the damage in this event to houses and their contents [Dowrick, 1991; Dowrick and Rhoades, 1990], and commercial and industrial property [Dowrick and Rhoades, 1993] have already been published. In the latter paper [Dowrick and Rhoades, 1993] our data on equipment (plant) and stock was limited mainly to damaged property; in the present paper we

1 Institute of Geological \& Nuclear Sciences, Lower Hutt (Fellow)

2 New Zealand Institute for Industrial Research \& Development, Lower Hutt find the complete distributions and the true mean damage ratios by including full data on undamaged property.

In this study commercial and industrial property is defined to mean equipment, plant, stock and other contents in and associated with commercial, industrial and institutional properties. The latter includes commercial residential property which incorporates hotels, motels, hostels and rest homes providing short term accommodation, and long term rental accommodation of more than one storey. Property of the above type that was government-owned at the time of the earthquake is also included (e.g. equipment in schools, post offices, telecommunications, electricity department buildings). Most public utility equipment is included (e.g. pumps in drainage pumphouses), the only known exceptions being the equipment external to the buildings at the Kawerau and Edgecumbe electricity supply switchyards, the utility networks (power and telecommunication lines and underground water and sewer pipes), and the Matahina Hydrodam and associated equipment. Equipment of a vehicular type is also excluded.

The degree of damage to any class of property at risk is often expressed as a damage ratio, i.e.

$$
\mathrm{D}_{\mathrm{r}}=\frac{\text { Cost of Damage to Property }}{\text { Value of Property }}
$$

The damage ratio is a function of intensity of shaking and in this paper is related to the MM intensity zones. 
The "Value of Property" used in Equation (1) has been defined variously in the literature, depending on what values were either available or appropriate, and may be the Replacement Value, Market Value, Indemnity Value, or Insured Value. The Replacement Value is preferable because it is more easily estimated and more consistent in its definition than the alternatives.

Because there are often so many individual items of equipment or stock at a given site, in general it is impracticable to find $D_{r}$ for every item individually (in contrast to buildings). The available data cover groups of items rather than individual items. We have chosen to call any such group a "parcel". A parcel may comprise all of the equipment in a given building or on a given site, or any part thereof, depending on the available data on damage costs or values of the property concerned.

\section{THE NATURE AND DISTRIBUTION OF THE EQUIPMENT AND STOCK}

In order that the replacement values and relative vulnerability of the total population of equipment and stock could be evaluated for each intensity zone, it was necessary to find out the number of parcels of each (damaged and undamaged) in each area of interest, and to obtain a description of the nature of each. To this end, insurance claim data were completed with data from owner/occupiers of uninsured property (mostly Government owned) and most of the damaged properties were visited. The final database included the following information for all parcels:
- address (location)

- date of construction of associated building (if any)

- vulnerability rating (class)

- damage cost

- value

The replacement value of each parcel of equipment at the time of the earthquake was obtained in one of three ways. In some cases replacement values were included in the claims of the Earthquake and War Damage Commission (EQC). If not, the replacement values were obtained from the owners or, failing that, estimated by the authors from the indemnity values allowing for depreciation.

Note that the MM8 Zone is not discussed in detail in this paper, because the number of data are too few and their geographical distribution too limited for analyses based on them to be statistically robust.

Estimates of the number of parcels and total value of equipment and stock in the MM7 and MM9 intensity zones are given in Table 1 .

The geographical distribution of equipment and stock within each intensity zone is similar to that for the associated buildings, as determined in our previous study [Dowrick and Rhoades, 1993]. The mean intensities for equipment and stock in the MM7 and MM9 intensity zones were found to be as follows: $\overline{\mathrm{I}}_{\mathrm{MM} 7} \approx 7.6$, and $\overline{\mathrm{I}}_{\mathrm{MM} 9} \approx 9.4$.

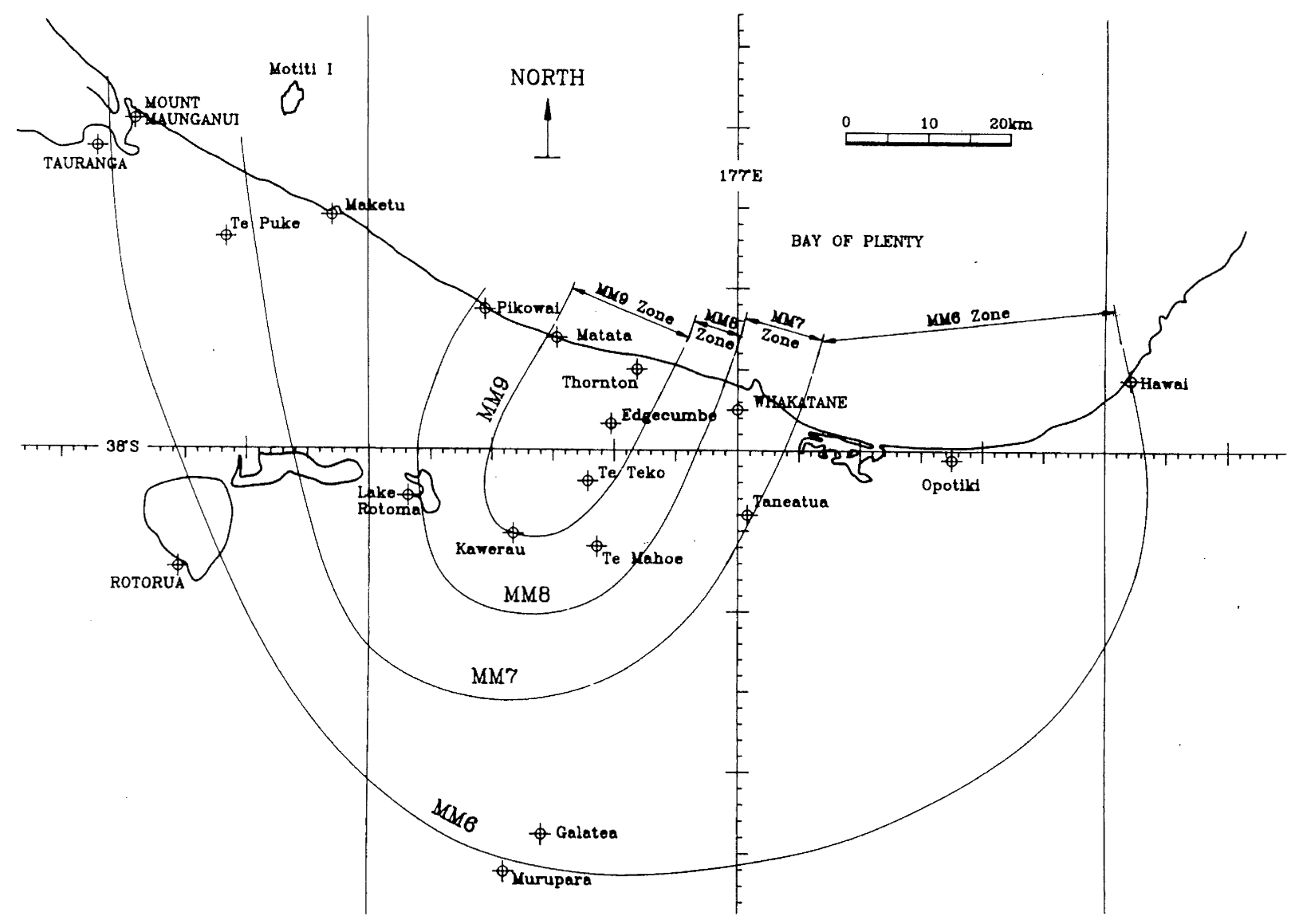

FIGURE I Map of inner isoseismals of the 1987 Edgecumbe earthquake (adapted from Lowry et al, 1989, reproduced from Dowrick, 1991, Dowrick and Rhoades, 1990 and 1993, by courtesy of John Wiley \& Sons Ltd). 
Table 1: Statistics of the inner intensity zones

\begin{tabular}{||c|c|c|c|c|}
\hline \multirow{4}{*}{$\begin{array}{c}\text { MM } \\
\text { Zntensity } \\
\text { Zone }\end{array}$} & \multicolumn{2}{|c|}{ Equipment } & \multicolumn{2}{|c|}{ Stock } \\
\cline { 2 - 5 } & $\begin{array}{c}\text { Number } \\
\text { of } \\
\text { Parcels }^{(2)}\end{array}$ & $\begin{array}{c}\text { Replacement } \\
\text { Value } \\
(\$ N Z)^{(3)} \\
\text { million }\end{array}$ & $\begin{array}{c}\text { Number } \\
\text { of } \\
\text { Parcels }\end{array}$ & $\begin{array}{c}\text { Indemnity } \\
\text { Value }^{(4)} \\
(\$ N)^{(3)} \\
\text { million }\end{array}$ \\
\hline MM7 Zone & 786 & 67 & 389 & 34 \\
MM9 Zone & 494 & 1826 & 213 & 68 \\
\hline
\end{tabular}

\section{Notes:}

(1) For definition of Zones see text and Figure 1.

(2) For definition of Parcels see text.

(3) 1987 dollar values.

(4) For definition of Indemnity Value see text.

Table 2: Equipment and stock in the 1987 Edgecumbe Earthquake. Summary of material damage costs, inclusive of insurance deductible (\$NZ 000)

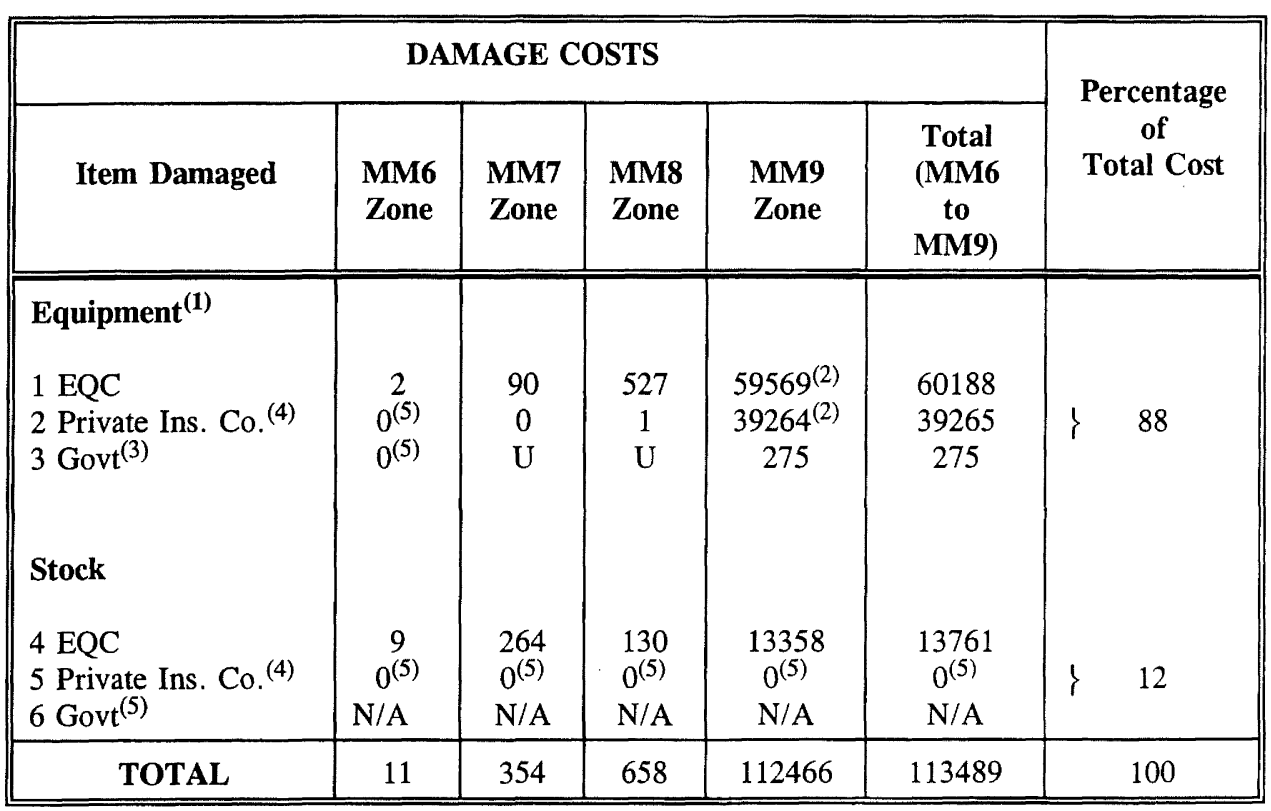

\section{Notes:}

(1) = Equipment nature and scope defined in text.

$(2)=$ Losses from Bay Milk factory have been adjusted for analysis purposes.

(3) = Govt means property owned by NZ Government underwritten by itself.

(4) = Insurance company losses incomplete, probably not underestimated significantly.

(5) = Uncertain, but believed to be near zero.

$\mathrm{U}=$ Unknown, but relatively small.

$\mathrm{N} / \mathrm{A}=$ Not applicable. 


\section{DAMAGE COSTS}

As described elsewhere [Dowrick and Rhoades, 1993], an attempt was made to find the complete cost of damage to commercial and industrial property within the MM6 isoseismal, and to distribute it geographically into intensity zones. A subset of this data, relating to the current study, is given in Table 2 . where it is seen that the total cost of damage to equipment and stock was \$NZ113 million. Damage to equipment and stock represented respectively $88 \%$ and $12 \%$ of the total cost.

The damage costs at one major site in the MM9 Zone, that of the Bay Milk Factory, bring an untidy aspect to this study. A dispute between the insurers and the insured was decided by a lump sum legal judgement which unfortunately obscured the true costs of damage for particular buildings and equipment items at this site. As a result, the validity of some of the Bay Milk data is questionable. The Bay Milk equipment data are very influential in the analysis because the damage levels and replacement values were both high. Hence we have presented some results for MM9 Zone equipment in two sets, i.e. including and excluding Bay Milk data. The losses for Bay Milk stock were not disputed, so the analyses of stock are not subject to this particular uncertainty.

\section{DAMAGE RATIOS}

\subsection{Damage Ratios for Equipment and Stock}

The damage ratio for each parcel of equipment was found relative to its Replacement Value, using the specific form of Equation (1) as follows:

$$
\mathrm{D}_{\mathrm{r}}=\frac{\text { Cost of Damage to a Parcel of Equipment }}{\text { Replacement Value of Parcel of Equipment }}
$$

The mean damage ratio for all parcels of a given class in a given $\mathrm{MM}$ intensity zone is of course a useful parameter. Considering all $\mathrm{N}$ parcels (damaged and undamaged) in an $\mathrm{MM}$ intensity zone, we give here two principal ways of defining the mean $\mathrm{D}_{\mathrm{r}}$. Firstly

$$
\overline{\mathrm{D}}_{\mathrm{r}}=\frac{\sum_{i=1}^{n}[\text { Cost of damage to parcel } i]}{\sum_{i=1}^{N}[\text { Value of parcel } i]}
$$

where $\mathrm{n}$ is the number of damaged parcels. Secondly

If derived from complete (i.e. damaged and undamaged) populations, $\bar{D}_{r}$ is appropriate for finding total losses for large populations of any type of property. For relatively

$$
\mathrm{D}_{\mathrm{rm}}=\frac{\sum_{i=1}^{n}\left[D_{r_{i}}\right]}{N}
$$

homogeneous populations $\bar{D}_{\mathrm{r}}$ and $\mathrm{D}_{\mathrm{rm}}$ tend to be similar in value, while for more inhomogeneous populations (with large ranges of replacement values and vulnerabilities) $\bar{D}_{\mathrm{r}}$ and $\mathrm{D}_{\mathrm{m}}$ may differ widely. In general $D_{r m}$ with its associated confidence limits is a more robust tool than $\bar{D}_{r}$, because $\bar{D}_{r}$ can be strongly affected by the damage level to a very few highvalue property items. However $\bar{D}_{\mathrm{r}}$ has the advantage that it is independent of the grouping of property items into parcels.
There is no standard terminology for classifying insured items; for the purposes of this study the following definitions were used:-

- Equipment: "Fixed" equipment or plant for tasks such as manufacturing, measuring, computing and storage. Contents of non-domestic buildings, except stock. (Mobile plant was excluded, eg. vehicles and mobile cranes).

- Stock: Mostly manufactured items stored in bulk prior to sale or hire.

For stock the readily available data was in indemnity value terms, so the following form of Equation (1) was used:

$$
\mathrm{D}_{\mathrm{r}}=\frac{\text { Indemnity Cost of Damage to Stock }}{\text { Indemnity Value of Stock }}
$$

where Indemnity Cost of Damage is the cost of repair to return the item to its Present Value without betterment. Indemnity Value was the New Zealand insurance industry measure of Present Value, being the Replacement Value minus normal physical depreciation. In case of Stock, the Indemnity Value usually equates to Replacement Value as it is usually recently made.

The values of $\bar{D}_{r}$ and $D_{r m}$ for various classes of equipment and stock are presented in Tables 3 and 4 . Considering the geographical distribution of property noted in Section 2, it was considered appropriate to plot the mean damage ratios at MM7.6 and MM9.4 for the MM7 and MM9 Zone intervals in Figure 2. At MM9 $\mathrm{D}_{\mathrm{rm}}$ for all equipment is 0.068 or 0.049 (including or excluding the Bay Milk data), while for all stock $\mathrm{D}_{\mathrm{rm}}$ is about twice as great at 0.109 . This difference is further discussed later

Various subsets of the data were considered. First, damage ratios of equipment and stock were classified according to their Use situation; five classes were adopted, namely industrial premises, shops, offices, halls and residential premises. It was found that only the first three of these classes had enough equipment parcels to provide meaningful statistics, while stock was mainly located at industrial premises and shops.

The mean damage ratio, $\mathrm{D}_{\mathrm{rm}}$, together with its $95 \%$ confidence limits for each of these Use classes is plotted in Figure 3, together with those for the total data sets. It can be seen that $\mathrm{D}_{\text {rm }}$ for industrial equipment is greatly affected by the Bay Milk data. Office equipment has a mean damage ratio $(0.037)$ which is much less than shop equipment $(0.061)$, but as the office population is relatively small the $95 \%$ confidence intervals overlap. Overall, there is no evidence that the damage ratio for equipment is related to Use class. Because of the highly nonsymmetric nature of the damage ratio distributions, the bootstrap method was used to estimate the confidence limits, the limits being quantiles of the distribution of the mean of 1000 random samples of size $\mathrm{N}$ with replacement from the empirical distribution of damage ratios.

In the case of stock, for all shops $D_{\mathrm{rm}}$ was 0.132 while for all industrial stock $\mathrm{D}_{\mathrm{rm}}$ was only 0.078 , with only a modest overiap of the confidence intervals. The difference between the damage ratios for the two classes of stock is significant at the $5 \%$ level. (Note that total separation of the $95 \%$ confidence intervals for the two classes is much more stringent than a $5 \%$ significance test for difference). 
Table 3: Basic statistics of the distribution of damage ratio for subsets of equipment and stock in the MM9 zone

\begin{tabular}{|c|c|c|c|c|c|c|}
\hline Subsets & $n$ & $N$ & $\hat{\mu}$ & $\hat{\sigma}^{2}$ & $D_{r m}$ & $\bar{D}_{r}$ \\
\hline \multicolumn{7}{|l|}{ Equipment in MM9 zone } \\
\hline All Uses & 227 & 484 & -2.95 & 2.37 & 0.068 & 0.054 \\
\hline All Uses (excl. Bay Milk) & 207 & 460 & -3.20 & 2.33 & 0.049 & 0.024 \\
\hline All Industrial & 103 & 174 & -3.08 & 3.09 & 0.101 & 0.054 \\
\hline All Industrial (excl. Bay Milk) & 83 & 150 & -3.72 & 2.45 & 0.046 & 0.023 \\
\hline All Shops & 53 & 111 & -2.96 & 2.15 & 0.061 & 0.184 \\
\hline All Offices & 11 & 38 & -3.19 & 2.73 & 0.037 & 0.009 \\
\hline \multicolumn{7}{|l|}{ Robust } \\
\hline All Uses & 90 & 210 & -3.32 & 2.11 & 0.044 & 0.019 \\
\hline All Uses (excl. Bay Milk) & 80 & 197 & -3.64 & 1.81 & 0.023 & 0.006 \\
\hline Industrial (excl. Bay Milk) & 44 & 89 & -4.31 & 1.83 & 0.014 & 0.006 \\
\hline \multicolumn{7}{|l|}{ Medium } \\
\hline All Uses & 124 & 256 & -2.91 & 2.29 & 0.068 & 0.068 \\
\hline All Uses (excl. Bay Milk) & 116 & 247 & -3.13 & 2.52 & 0.052 & 0.031 \\
\hline Industrial (excl. Bay Milk) & 33 & 51 & -3.50 & 3.60 & 0.061 & 0.030 \\
\hline Shops & 51 & 103 & -3.00 & 2.12 & 0.060 & 0.187 \\
\hline Offices & 10 & 32 & -3.49 & 1.98 & 0.020 & 0.006 \\
\hline \multicolumn{7}{|l|}{ Fragile } \\
\hline All Uses & 13 & 18 & -0.83 & 0.57 & 0.358 & 0.603 \\
\hline All uses (excl. Bay Milk) & 11 & 16 & -0.90 & 0.64 & 0.320 & 0.479 \\
\hline Industrial (excl. Bay Milk) & 6 & 10 & -0.77 & 0.41 & 0.276 & 0.523 \\
\hline \multicolumn{7}{|l|}{ Stock in MM9 zone } \\
\hline All Uses & 120 & 212 & -2.28 & 1.51 & 0.109 & 0.195 \\
\hline All Industrial & 40 & 81 & -2.55 & 1.69 & 0.078 & 0.209 \\
\hline All Shops & 70 & 113 & -2.17 & 1.46 & 0.132 & 0.079 \\
\hline \multicolumn{7}{|l|}{ Robust } \\
\hline All Uses & 23 & 82 & -3.41 & 1.09 & 0.015 & 0.022 \\
\hline Industrial & 19 & 54 & -3.33 & 1,25 & 0.021 & 0.023 \\
\hline Shops & 4 & 25 & -3.82 & 0.25 & 0.004 & 0.003 \\
\hline \multicolumn{7}{|l|}{ Medium } \\
\hline All Uses & 35 & 53 & -2.54 & 1.42 & 0.091 & 0.053 \\
\hline Industrial & 15 & 21 & -2.19 & 1.80 & 0.142 & 0.061 \\
\hline Shops & 19 & 30 & -2.71 & 0.93 & 0.061 & 0.048 \\
\hline Fragile & & & & & 0.223 & 0.478 \\
\hline All Uses & 62 & 77 & -1.73 & 1.14 & & \\
\hline Industrial & 6 & 6 & -1.11 & 0.69 & 0.374 & 0.520 \\
\hline Shops & 47 & 58 & -1.80 & 1.34 & 0.223 & 0.161 \\
\hline
\end{tabular}

The relative vulnerability to earthquakes of any given thing is of course dependent on its nature, e.g. whether it has been designed specifically to resist earthquakes. Hence the relative vulnerabilities of the various subsets of equipment and stock. plotted on Figure 3 are a function of the nature of the particular parcels comprising the data. The broad Use classes adopted here do not define the resistive nature of the parcels of equipment or stock that they could contain.

In order to examine the earthquake resistive nature more closely, but still with workably simple classes, each parcel of equipment and stock was placed (a priori) in one of three classes of relative earthquake vulnerability, labelled, Robust, Medium or Fragile. By a priori it is meant that the classification was assigned from the physical nature and/or situation of the particular parcel without reference to its damage ratio in this event. Various factors were taken into account, including whether the parcel was designed for earthquake resistance or not, e.g. stainless steel tanks in the food processing industry were not designed for earthquakes and were clearly in the Fragile class. Inherently tough items such as rolls of newsprint, pumps and some non-brittle items such as clothing. were classed as Robust. Unsecured brittle items such as most ceramics or glassware are obviously Fragile. The situation of some items may affect their vulnerability, such as whether they are secured against falling, e.g. glassware. mechanical equipment and desk-top computers. It is encouraging to find that in the last few years a number of laboratories in New Zealand have devised "operator-friendly" means of securing glassware items which are kept on shelves or benches. but which need to be moved quite frequently. A range of examples of the vulnerability classes adopted for this study is given in Table 5 .

While the criteria for the vulnerability of many items were reasonably definitive. subjective judgements variously arise. such as for items which seem to be near a class boundary. e. whether Robust or Medium. The subjectivity is greatest when there are many disparate items of equipment or stock within a given parcel. Such cases can formally be dealt with by weighting the contribution of each item according to its replacement value. In this study, with so many parcels to be 
Table 4: Basic statistics of the distribution of damage ratio for subsets of equipment and stock in the MM7 zone

\begin{tabular}{|c|c|c|c|c|c|c|}
\hline Subset & $n$ & $N$ & $\hat{\mu}$ & $\hat{\sigma}^{2}$ & $D_{r m}$ & $\bar{D}_{r}$ \\
\hline Equipment in MM7 zone & & & & & & \\
\hline All Uses & 66 & 764 & -4.52 & 2.22 & 0.0030 & 0.0015 \\
\hline All Industrial & 11 & 168 & -5.55 & 1.16 & 0.0004 & 0.0006 \\
\hline All Shops & 31 & 247 & -4.04 & 2.67 & 0.0073 & 0.0059 \\
\hline All Offices & 3 & 102 & -2.93 & 0.52 & 0.0019 & 0.0008 \\
\hline \multicolumn{7}{|l|}{ Robust } \\
\hline All Uses & 16 & 254 & -5.23 & 1.41 & 0.0006 & 0.0005 \\
\hline Industrial & 4 & 97 & -5.57 & 1.30 & 0.0002 & 0.0004 \\
\hline \multicolumn{7}{|l|}{ Medium } \\
\hline All Uses & 46 & 486 & -4.25 & 2.02 & 0.0037 & 0.0022 \\
\hline Industrial & 5 & 66 & -5.07 & 0.94 & 0.0007 & 0.0008 \\
\hline Shops & 29 & 237 & -4.12 & 2.55 & 0.0062 & 0.0057 \\
\hline Offices & 3 & 87 & -2.93 & 0.52 & 0.0022 & 0.0009 \\
\hline \multicolumn{7}{|l|}{ Fragile } \\
\hline All Uses & 4 & 24 & -4.76 & 6.92 & 0.0137 & 0.0019 \\
\hline Industrial & 2 & 5 & -6.71 & 0.08 & 0.0005 & 0.0012 \\
\hline \multicolumn{7}{|l|}{ Stock in MM7 zone } \\
\hline All Uses & 78 & 389 & -3.25 & 1.93 & 0.0209 & 0.0079 \\
\hline All Industrial & 12 & 122 & -2.92 & 4.61 & 0.0209 & 0.0066 \\
\hline All Shops & 62 & 245 & -3.44 & 1.46 & 0.0171 & 0.0087 \\
\hline \multicolumn{7}{|l|}{ Robust } \\
\hline All Uses & 6 & 165 & -5.23 & 1.03 & 0.0003 & 0.0004 \\
\hline Industrial & 4 & 80 & -5.35 & 1.18 & 0.0004 & 0.0004 \\
\hline Shops & 2 & 82 & -4.99 & 1.45 & 0.0002 & 0.0003 \\
\hline \multicolumn{7}{|l|}{ Medium } \\
\hline All Uses & 23 & 85 & -3.71 & 1.77 & 0.0153 & 0.0070 \\
\hline Industrial & 5 & 26 & -3.07 & 6.03 & 0.0308 & 0.0079 \\
\hline Shops & 18 & 58 & -3.89 & 0.72 & 0.0086 & 0.0066 \\
\hline \multicolumn{7}{|l|}{ Fragile } \\
\hline All Uses & 49 & 139 & -2.81 & 1.63 & 0.0486 & 0.0260 \\
\hline Industrial & 3 & 16 & -0.32 & 0.11 & 0.1072 & 0.0482 \\
\hline Shops & 42 & 105 & -3.18 & 1.56 & 0.0349 & 0.0202 \\
\hline
\end{tabular}

considered, this could only be done very coarsely. Because of the wide variety of items of equipment used in shops and offices, the vulnerability of parcels of equipment in shops and offices was assigned as Medium in most instances.

The subsets of data according to Use, as presented in Figure 3, were subdivided further according to vulnerability and the resulting smaller subsets were analysed for means and distributions. The results are shown in Figure 4. It is seen that the values of $D_{r m}$ for the three vulnerability classes are very different. $\quad \mathrm{D}_{\mathrm{rm}}$ for all Fragile (F) equipment is 6.1 times that for Medium (M) equipment, while $\mathrm{D}_{\mathrm{rm}}$ for Medium equipment is 2.3 times that for Robust (R) equipment. For all stock the ratios of $D_{r m}(F)$ to $D_{r m}(M)$ and $D_{r m}(M)$ to $D_{r m}(R)$ are 2.5 and 6.1 respectively. The relative values of $D_{r m}$ as a function of vulnerability varies for the different Use classes, but some of the subsets are quite small, so that the $95 \%$ confidence limits are quite large (not shown). However the general pattern is quite clear for all the subsets plotted (Figure 4) except for the Office equipment.

As already noted, the overall mean damage ratio for stock at MM9 is about twice that for equipment. The explanation for this is shown in Figure 4 where the breakdown of these two types of property into vulnerability classes is given. It is seen that in our data sets about a third of the stock was Fragile, but only about 4 percent of the equipment. This big difference in the proportion of Fragile parcels is very influential in obtaining the overall $\mathrm{D}_{\mathrm{rm}}$, even though Fragile equipment was actually more severely damaged than Fragile stock. This outweighed the contributions of the Medium and Robust parcels to the two overall $\mathrm{D}_{\mathrm{rm}}$ values. It is thus obvious that for any given population of equipment or stock it is important to quantify the proportions of parcels which are Robust, Medium and Fragile will greatly affect the level of damage sustained in earthquake shaking

As noted above, in most cases Office equipment was classified as Medium vulnerability and was considered likely to be of a similar nature overall to shop equipment. As seen on Figure 4, $D_{\mathrm{rm}}$ for Office equipment was much less than $D_{\mathrm{rm}}$ for the other two Medium subsets (Industrial and Shops), being similar in value to $\mathrm{D}_{\mathrm{rm}}$ for the Robust equipment subsets. This result is probably explained by the fact that the Office subset is quite small (only 32 parcels compared with 103 shop equipment parcels) so that the estimate of the mean $D_{r m}$ is not very precise. Also most of the offices in the MM9 Zone were located in Kawerau at the fringe of the MM9 Zone, while a bigger percentage of the shops and industrial sites were nearer than Kawerau to the fault rupture at the centre of the MM9 Zone. 


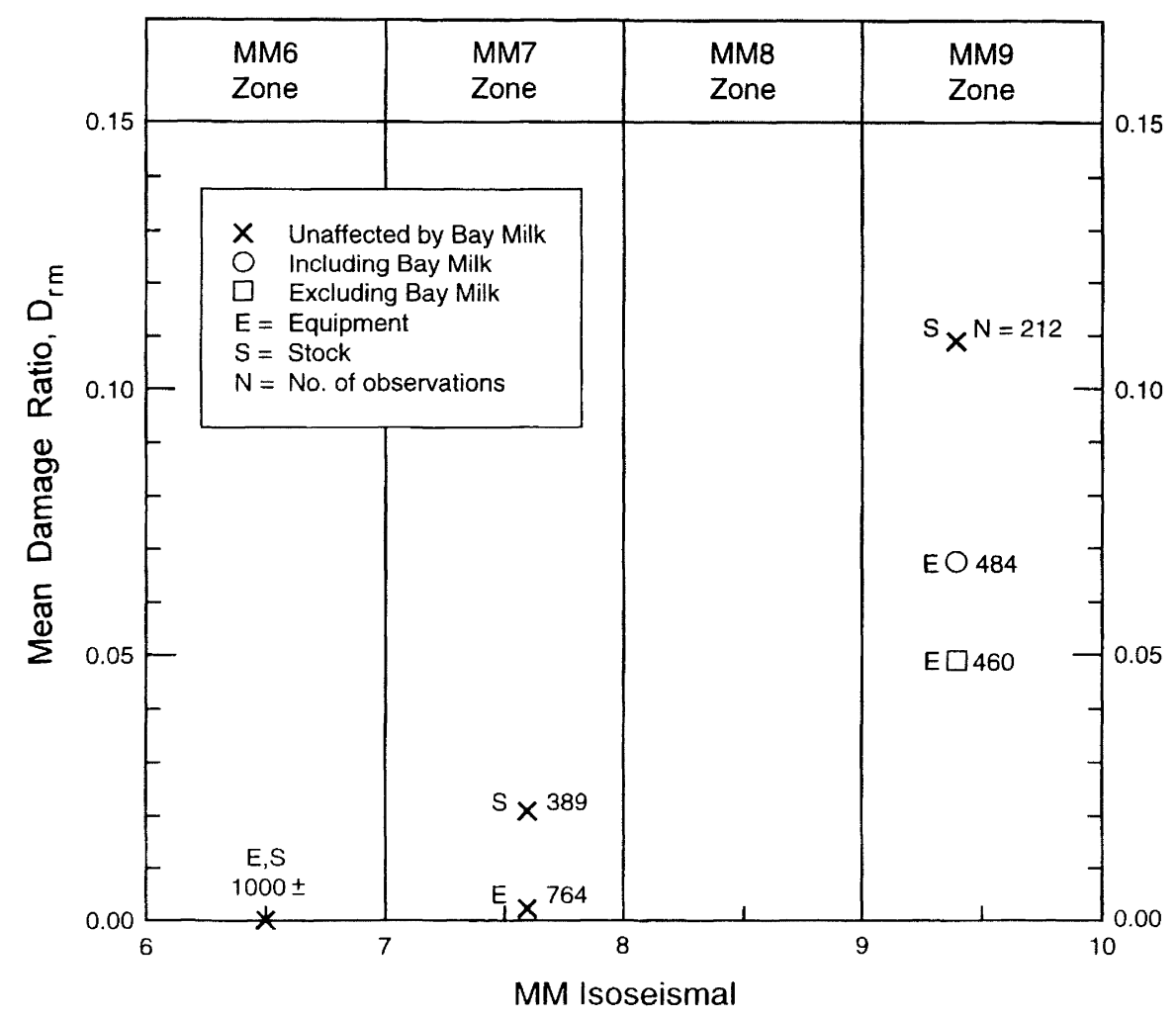

FIGURE 2 Overall mean damage ratios for equipment and stock as a function of intensity in the 1987 Edgecumbe earthquake.

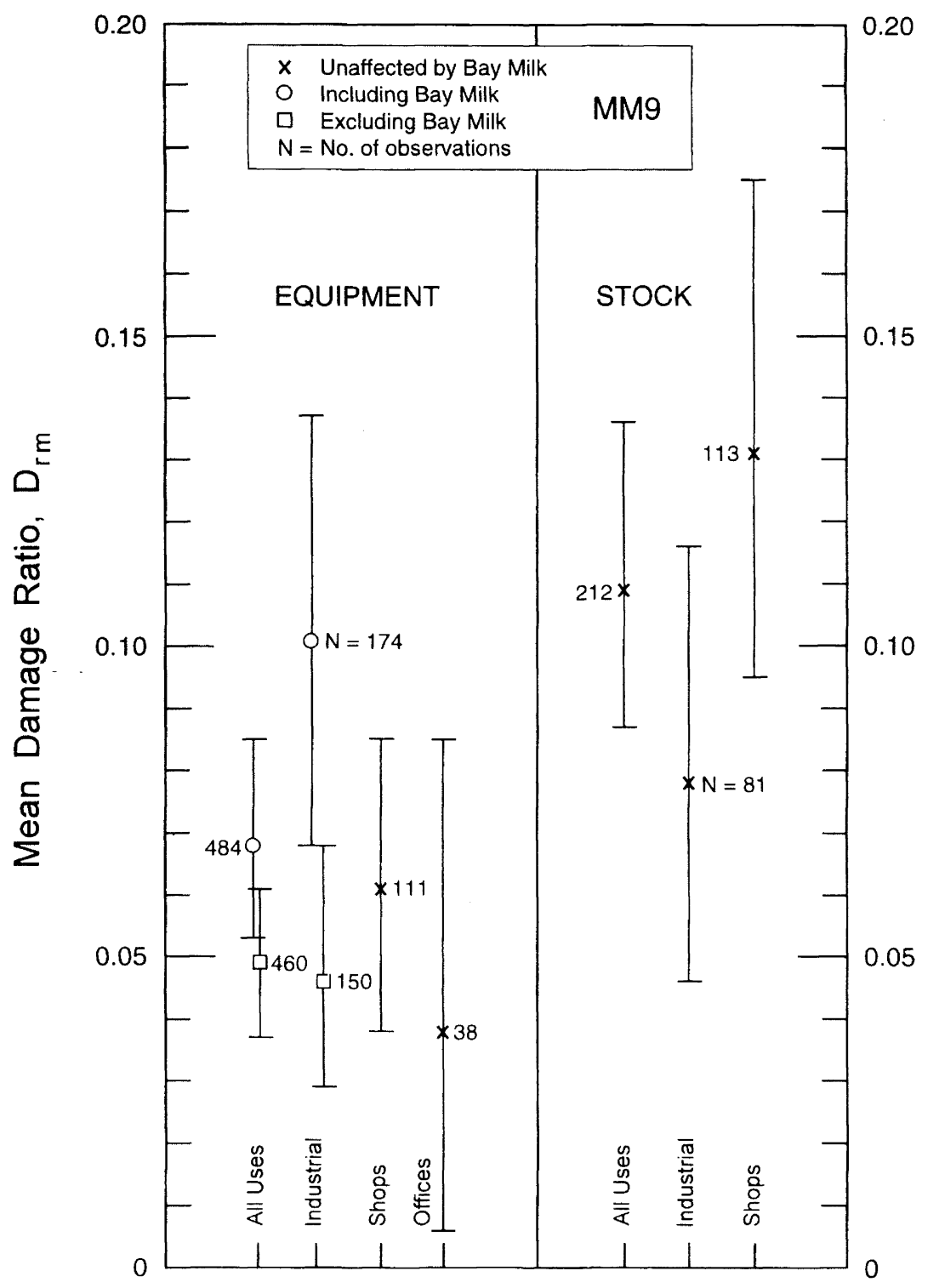

FIGURE 3 Mean damage ratios for equipment and stock in various Use classes in the MM9 Zone of 1987 Edgecumbe earthquake. The error bars are 95\% confidence limits for the mean, determined by bootstrap resampling from the empirical distribution of damage ratios. 
Table 5: General Characteristics and Examples of Vulnerability Classification of Equipment and Stock

\begin{tabular}{|c|c|c|}
\hline Robust & Medium & Fragile \\
\hline $\begin{array}{l}\text { General Characteristics } \\
\text { Designed for earthquakes } \\
\text { Inherently tough } \\
\text { Well restrained against falling, } \\
\text { or overturning; low aspect } \\
\text { ratio, H/B* } \\
\text { Thick members, anti-buckling }\end{array}$ & $\begin{array}{l}\text { Designed for earthquakes } \\
\text { Intermediate between } \\
\text { Robust and Fragile }\end{array}$ & $\begin{array}{l}\text { Not designed for earthquake } \\
\text { Inherently brittle } \\
\text { Not restrained against } \\
\text { overturning and of high } \\
\text { aspect ratio, H/B } \\
\text { Thin members, likely to } \\
\text { buckle }\end{array}$ \\
\hline $\begin{array}{l}\text { Equipment } \\
\text { Heavy fixed equipment: } \\
\text { Pumps } \\
\text { Generators } \\
\text { Turbines } \\
\text { Transformers } \\
\text { Handling equipment for } \\
\text { heavy/bulky materials } \\
\text { Most engineering workshops } \\
\text { Some furniture } \\
\text { Motels, kindergartens, churches }\end{array}$ & $\begin{array}{l}\text { Some computers } \\
\text { Some transformers } \\
\text { Some stainless steel food } \\
\text { processors equipment } \\
\text { Some furniture } \\
\text { Most offices \& shops } \\
\text { Mix of Robust, Medium } \\
\text { and Fragile }\end{array}$ & $\begin{array}{l}\text { Loose equipment, such as } \\
\quad \text { Computers (some) } \\
\quad \text { Microscopes } \\
\quad \text { Laboratory glassware }\end{array}$ \\
\hline $\begin{array}{l}\qquad \text { Stock } \\
\text { Timber logs } \\
\text { Heavy processed timber } \\
\text { Paper products } \\
\text { Clothing } \\
\text { Motor Vehicles } \\
\text { Chainsaws }\end{array}$ & $\begin{array}{l}\text { Some food } \\
\text { Some pharmacy stock } \\
\text { Mix of Robust, Medium } \\
\text { and Fragile }\end{array}$ & $\begin{array}{l}\text { Most food and drink } \\
\text { Chilled food** } \\
\text { Most pharmacy stock } \\
\text { Most engineering workshops } \\
\text { Paint }\end{array}$ \\
\hline
\end{tabular}

* $\quad \mathrm{H} / \mathrm{B}=$ Height/Breadth (for centre of mass)

** Vulnerable to power failure

Comparing $\mathrm{D}_{\mathrm{rm}}$ for the Fragile and Robust subsets, the ratio of $D_{\mathrm{rm}}(\mathrm{F})$ to $\mathrm{D}_{\mathrm{rm}}(\mathrm{R})$ for all equipment in the MM9 Zone is approximately 14 (or 8 including Bay Milk). Although $D_{\mathrm{rm}}(\mathrm{F})$ is based on a small subset, a large difference between the seismic resistance of these two extreme vulnerability classes is of course to be expected. This result suggests that at intensity MM9 earthquake protection of equipment could reduce the damage levels by about an order of magnitude (on average) for a wide range of unprotected highly vulnerable equipment (where "operator-friendly" protection systems can be found).
A similar comparison for all stock at MM9 shows that the ratio of $D_{r m}(F)$ to $D_{r m}(R)$ is 15 , a similar difference to that found for equipment. Unfortunately it is not practicable to protect most items of Fragile stock (generally in shops), but this result is of value for insurance purposes.

The foregoing discussion has concentrated on the results for the strongest intensity Zone (MM9), but it is of interest also to consider the relative damage levels in the MM7 Zone. It was found that the ratio of $D_{r m}(F)$ to $D_{r m}(R)$ for all equipment was 


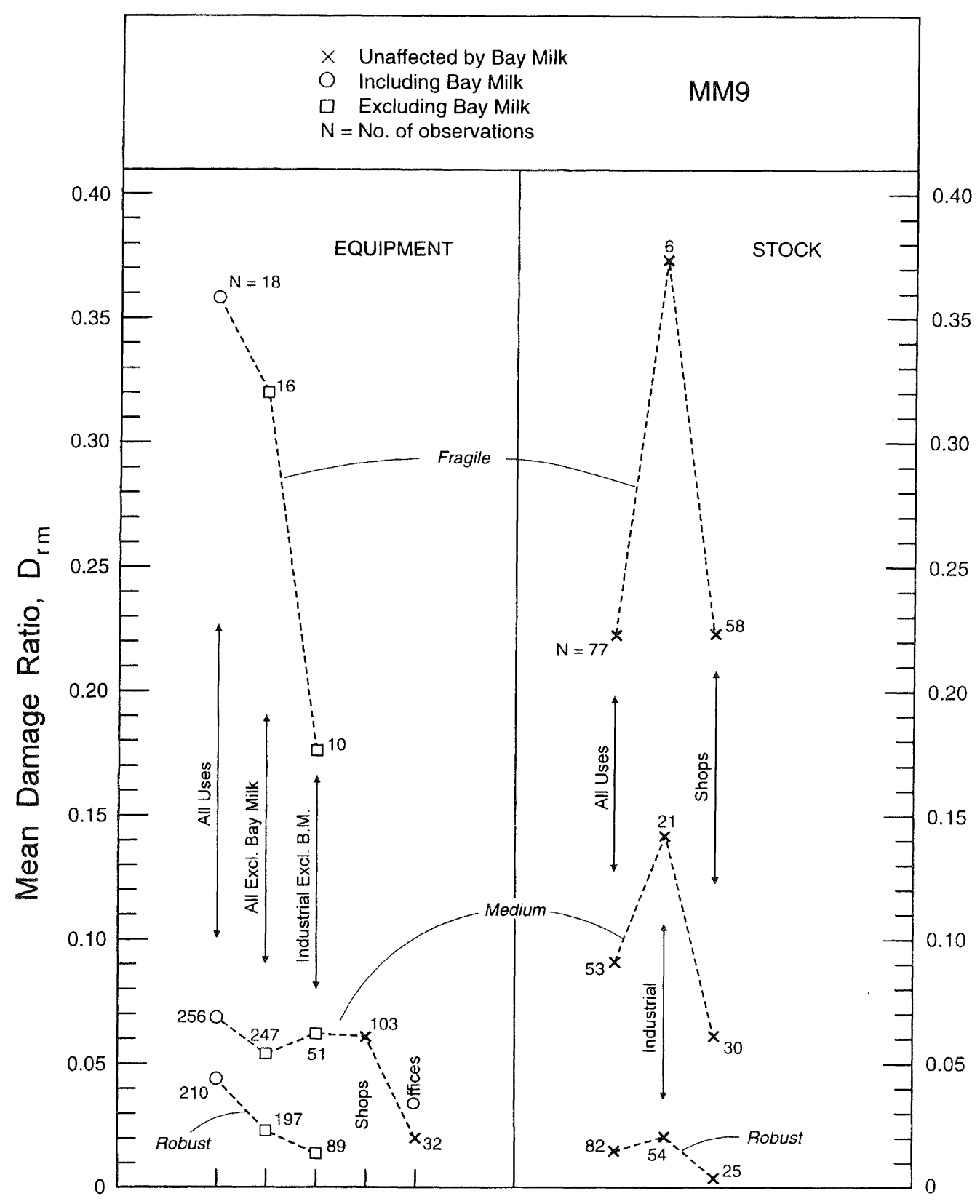

FIGURE 4 Mean damage ratios for equipment and stock in three vulnerability classes for various Use classes in the MM9 Zone of the 1987 Edgecumbe earthquake.

23 and for all stock was 160 . These ratios are larger than the equivalent ones for the MM9 Zone, as is to be expected, i.e. the threshold intensity of shaking for damage to occur to fragile items is lower than for robust ones. This fact is fundamental to the intensity scale.

Finally, it is of interest to compare the vulnerability of equipment with that of the associated buildings in this earthquake. In the MM9 Zone (but excluding Bay Milk) $D_{\text {rm }}$ for post-code $(1935+)$ single storey commercial and industrial buildings was 0.052 (349 buildings) [Dowrick and Rhoades, in prep.], while for equipment of all uses (excluding Bay Milk) of Medium vulnerability $\mathrm{D}_{\mathrm{rm}}$ was also 0.052 (247 parcels). But $\mathrm{D}_{\mathrm{rm}}$ for Robust and Fragile equipment is very different from the above values. It is apparent that in New Zealand post-code single storey commercial and industrial buildings and Medium vulnerability equipment have similar earthquake resistance capabilities. Further support for this is given by the fact that the scatter for these two data sets is also very similar, i.e. $\sigma^{2}$ is 2.7 for the buildings and 2.5 for the equipment.

\subsection{Statistical Distributions of Damage Ratios}

Other studies by the authors [Dowrick, 1991; Dowrick and Rhoades, 1991, 1993] of damage in this earthquake found the shape of the statistical distribution of damage ratios for several classes of property to be lognormal. The lognormal distribution has the density function

$$
f(x)=\frac{1}{\sigma x \sqrt{2 \pi}} \exp \left[-\frac{1}{2}\left(\log _{e} x-\mu\right)^{2} / \sigma^{2}\right] \quad x>0
$$

Here the parameters $\mu$ and $\sigma$ are estimated by the sample mean and standard deviation of the natural $\log$ of the damage ratio. 
The estimates of the parameters $\mu$ and $\sigma$, found for the various data sets, are given in Tables 3 and 4 . Also tabulated are the numbers of damaged parcels $\mathrm{n}$, and the total population (damaged + undamaged ) $\mathrm{N}$.

Tables 3 and 4 show that $\sigma^{2}$ for stock and equipment are about the same for the MM9 Zone as for the MM7 Zone, except for one "rogue" value (Fragile equipment in the MM7 Zone), which we attribute to an artifact of the small number of damaged parcels in the subset.

In this study, a significant number of property items in the MM9 Zone attained the damage ratio upper limit of one. The lognormal distribution, which is unbounded at the top end, can only be used to describe that part of the damage ratio distribution which is below one. To avoid bias in estimating $\mu$ it was necessary to use a trimmed mean, using the method described in a previous study [Dowrick and Rhoades, 1993]. The data are fitted well by the lognormal distribution as shown in Figure 5, where the empirical and fitted lognormal cumulative probability distributions are plotted for each of equipment and stock at MM7 and MM9. Good lognormal fits are obtained for our larger subsets, and reasonable fits are made for subsets with populations as small as $N \approx 40$.

On Figure 6 are plotted the 95\% confidence limits of the empirical cumulative probability distributions for the three vulnerability classes of stock in the MM9 Zone. The confidence limits at a given value of $D_{r}$ are calculated as $p \pm 2[(1-p) / N]^{1 / 2}$, where $p$ is the proportion of parcels in the class with damage ratio exceeding $D_{r}$. This formula is based on the usual normal approximation to the binomial distribution.

These limits for the Robust and Medium classes, are clearly separated, while there is a modest overlap between the Medium and Fragile classes, especially at the low end of the distribution. This occurs because the majority of stock parcels in both the Medium and Fragile classes sustained some damage at MM9. The separation of these two distributions at damage ratios greater than 0.1 is quite good, and shows that the difference between Medium and Fragile stock is easily significant at the $5 \%$ level.

\subsection{Damage Ratio as a Function of Replacement Value}

In Figure 7 are plotted the damage ratio for each parcel of equipment in the MM9 zone against its Replacement Value (RV), using both a linear and a log scale for the RV axis as an aid to discerning any trends. It is apparent that most of the scatter in $D_{r}$ in this data set is associated with parcels of small RV (i.e. RV less than about $\$ 10,000$ ). This pattern also occurs in all of the Robust and Medium subsets but not in the Fragile ones. This suggests that small value equipment in general is less likely to be provided with some kind of earthquake protection, either because of its shape, or because of the way it is used (i.e. it may not be secured in place).

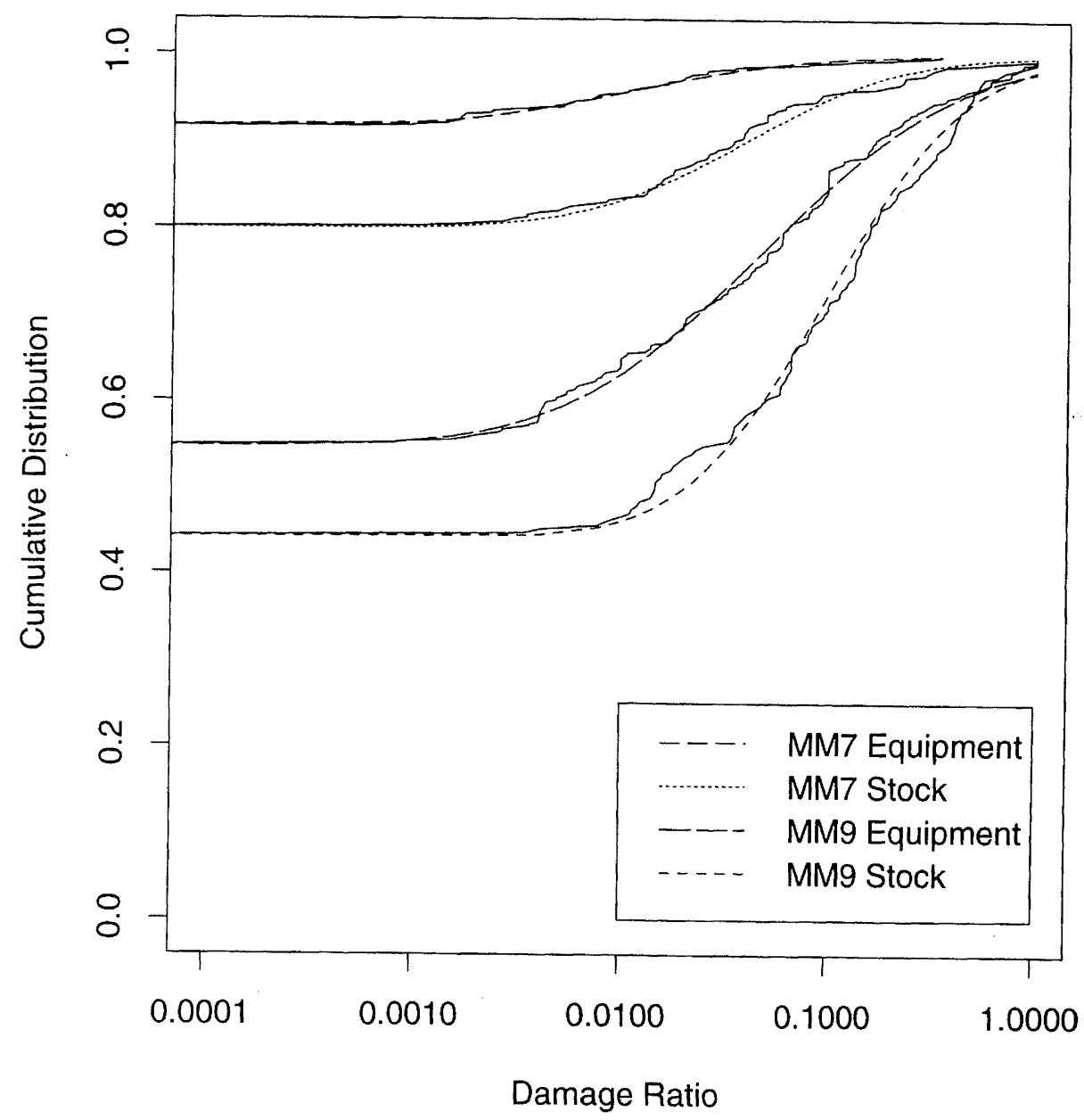

FIGURE 5 Empirical and fitted lognormal cumulative probability distributions for equipment and stock, in the MM7 and MM9 Zones of the 1987 Edgecumbe earthquake. 


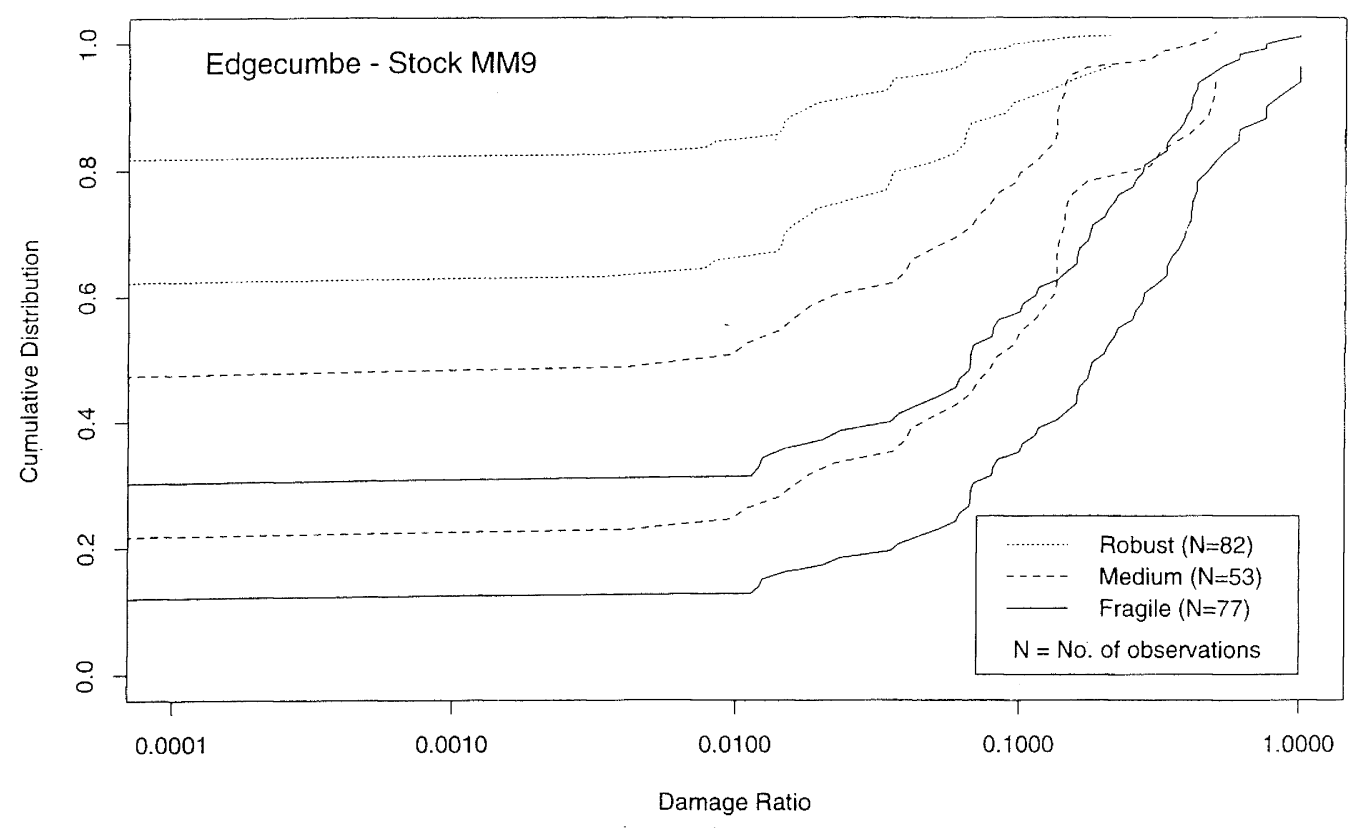

FIGURE 695 percent confidence limits of the cumulative probability distributions for the three vulnerability classes of stock in the MM9 Zone of the 1987 Edgecumbe earthquake.

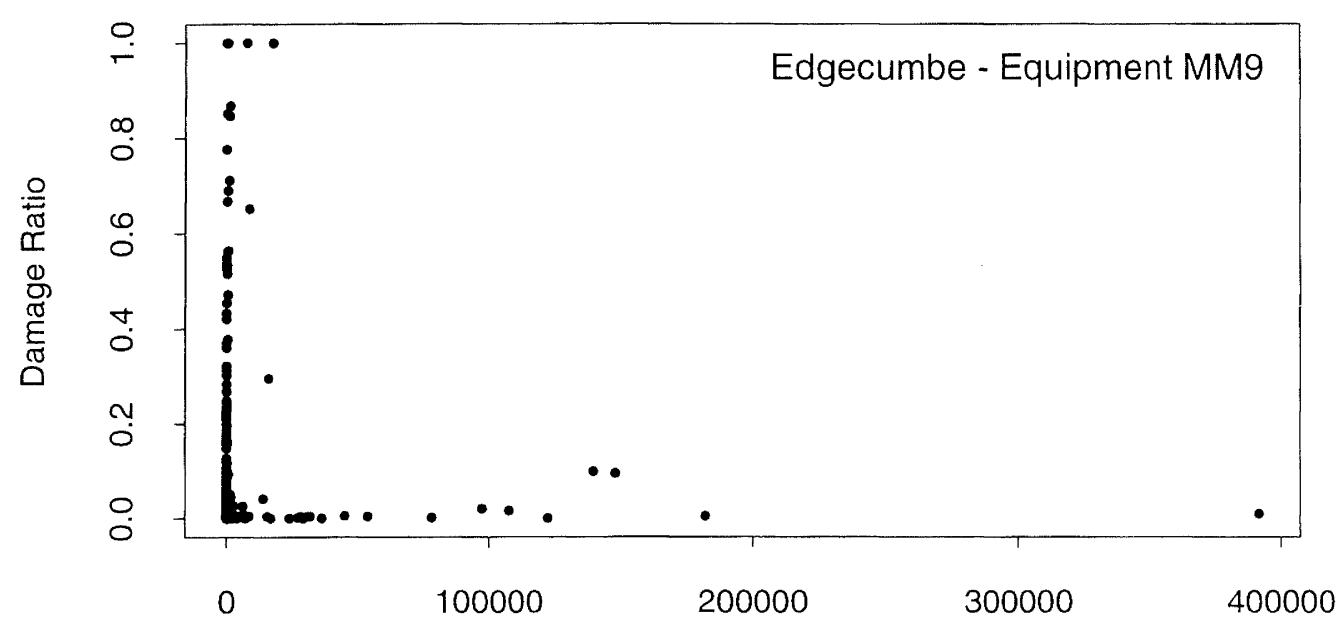

Replacement value $(\$ 000)$

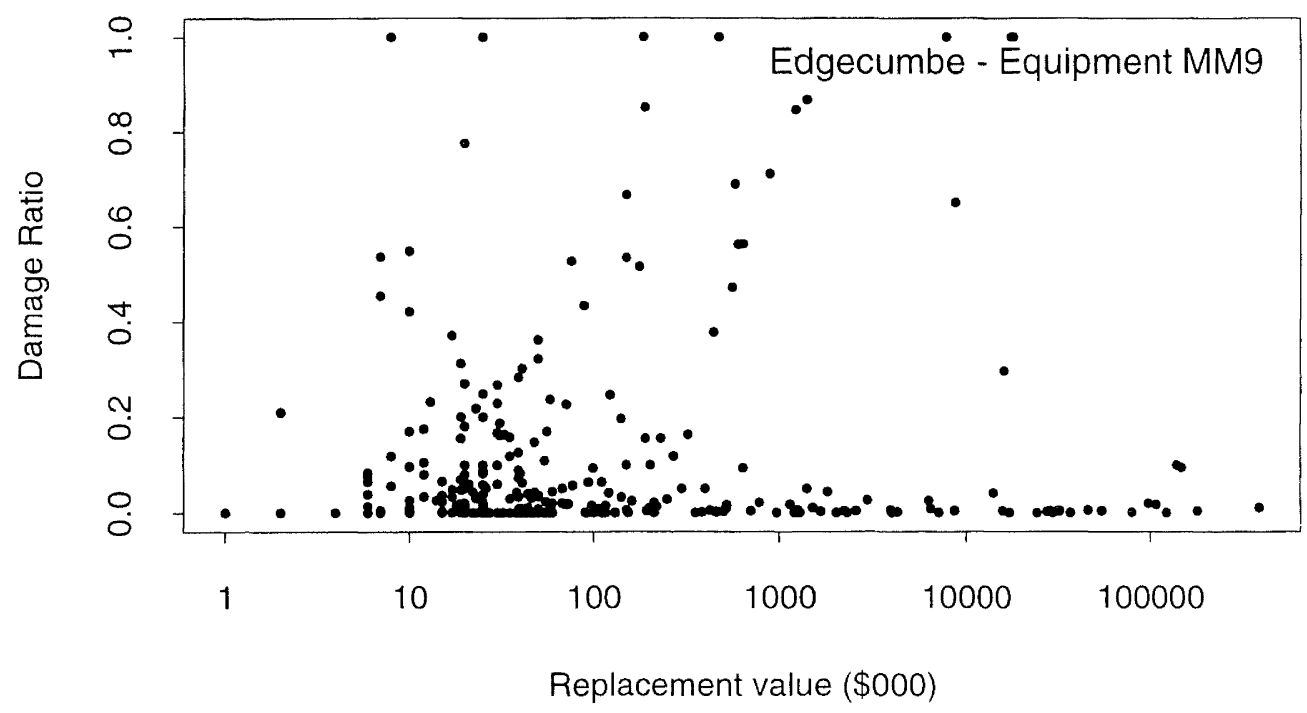

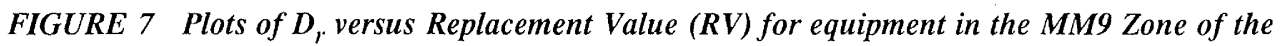
1987 Edgecumbe earthquake, using (a) normal $R V$ axis and (b) $\log R V$ axis. 
Certainly the pattern of the data plots in Figure 7 is very different from that of the very homogeneous data provided by single storey timber houses (with good inherent earthquake resistance) in Napier in the 1931 Hawke's Bay Earthquake [Lowry et al, 1989]. As shown in Figure 8, the scatter of the latter data is smaller and is much more uniformly distributed as a function of RV, so much so that a nearly horizontal best fit line is obtained. A tendency for $D_{r}$ to increase at small $R V$ is seen in Figure 8, but is much less marked than for equipment. As discussed elsewhere [Dowrick et al, 1995] in the case of Napier houses there is some reason to believe that the RV's of the small houses tend to be underestimated, which would account for at least some of this effect.

\section{PROPORTION OF PARCELS DAMAGED}

In assessing the statistical parameters of damage ratios in a given region it is important to account for the undamaged parcels of property as well as the damaged ones. This is seen by the intluence of the values of the numbers of damaged parcels (n) and the total number (N) in the various subsets of data discussed in Section 4. In our data an undamaged parcel is defined as one for which the damage cost was below the insurance deductible, being the larger of $\$ 200$ or $1 \%$ of the damage cost.

The proportion of parcels damaged, $\mathrm{n} / \mathrm{N}$, in each $\mathrm{MM}$ intensity zone has been plotted in Figure 9 for the three vulnerability classes of both equipment and stock, using the relevant values of $\mathrm{n}$ and $\mathrm{N}$ from Tables 3 and 4 . As with $\mathrm{D}_{\mathrm{rm}}$ discussed above, it is seen that $\mathrm{n} / \mathrm{N}$ is very sensitive to the vulnerability class. At MM7 n/N is $35 \%$ for Fragile stock and only $4 \%$ for Robust stock, while at MM9 the corresponding $\mathrm{n} / \mathrm{N}$ values are $80 \%$ and $28 \%$. Somewhat in contrast, $\mathrm{n} / \mathrm{N}$ for equipment is seen in Figure 9 to be quite a lot less sensitive to vulnerability class.
As a further comparison we note that for the associated postcode $(1935+)$ commercial and industrial single storey buildings in the same earthquake, $\mathrm{n} / \mathrm{N}$ was $48 \%$ (349 buildings) at MM9, compared with $47 \%$ for Medium vulnerability equipment. This is further evidence of the close similarity of these two types of property; the similarities in their $\mathrm{D}_{\mathrm{rm}}$ and $\sigma^{2}$ values were discussed above.

\section{CONCLUSIONS}

The following conclusions should be read bearing in mind that they result from the study of only one earthquake:

1 A summary has been made of nearly all the material damage costs to commercial and industrial equipment and stock resulting from the 1987 Edgecumbe earthquake. The total cost for equipment and stock was c. $\$(\mathrm{NZ}) 113$ million. Eighty eight percent of this cost was from damage to equipment.

2 Great care was taken to account for the total population of property (undamaged as well as damaged), because neglecting undamaged property will obviously lead to overestimating mean damage ratios, as illustrated by comparing $\mathrm{n}$ and $\mathrm{N}$ in Tables 3 and 4 . The percentage of parcels damaged is strongly dependent on the vulnerability class. At MM9 $80 \%$ of Fragile stock parcels were damaged, compared with $28 \%$ of Robust stock parcels.

3 Damage ratios and their statistical distributions have been estimated for various classes of equipment and stock for two Modified Mercalli intensities. The mean damage ratio $D_{r m}$ ranges from 0.0002 for Robust equipment or stock in the MM7 Zone to $>0.2$ for most subsets of Fragile equipment or stock in the MM9 Zone.

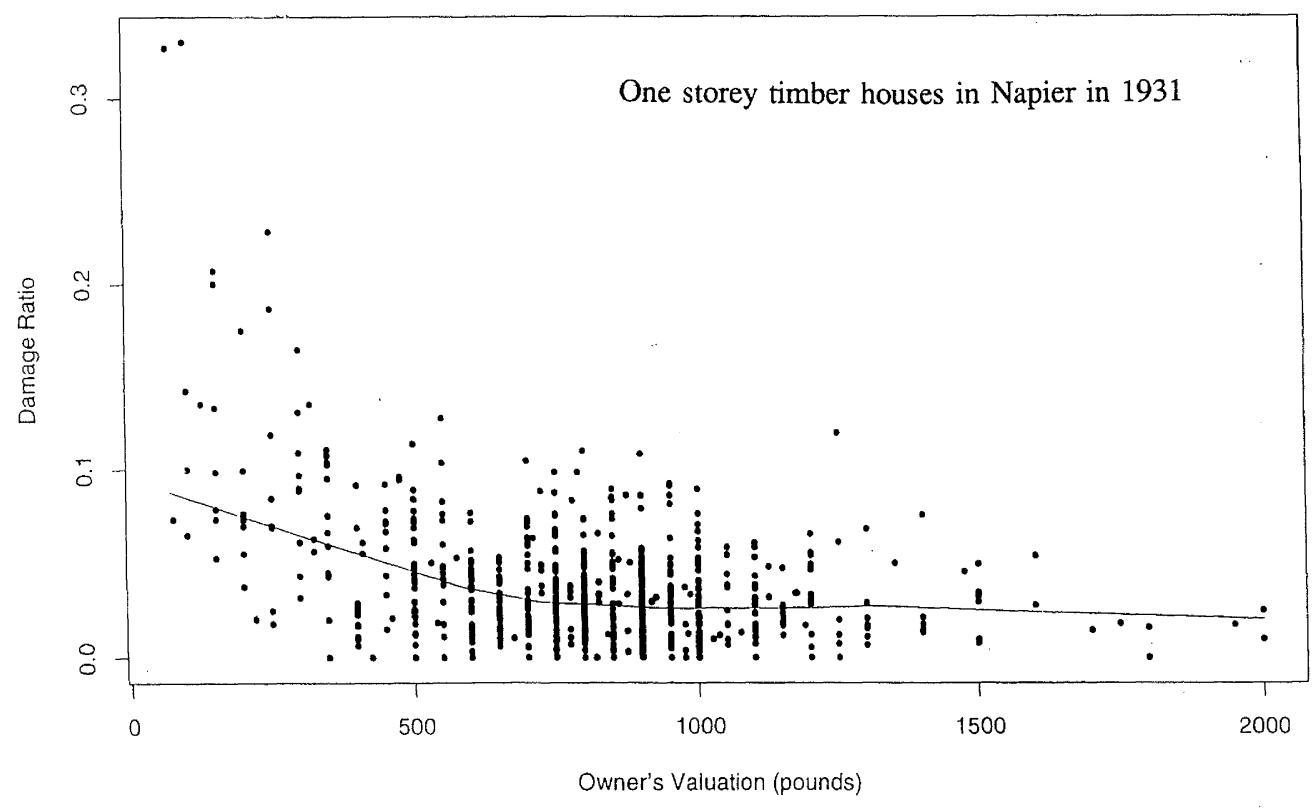

FIGURE 8 Plot of $D_{r}$ versus Owner's Valuation ( $\approx$ Replacement Value) for single storey timber houses on soft ground in Napier in the $M_{s} 7.8$ Hawke's Bay earthquake of 1931. A "robust fit" of the mean damage ratio curve is also plotted (From Dowrick et al, 1995). 


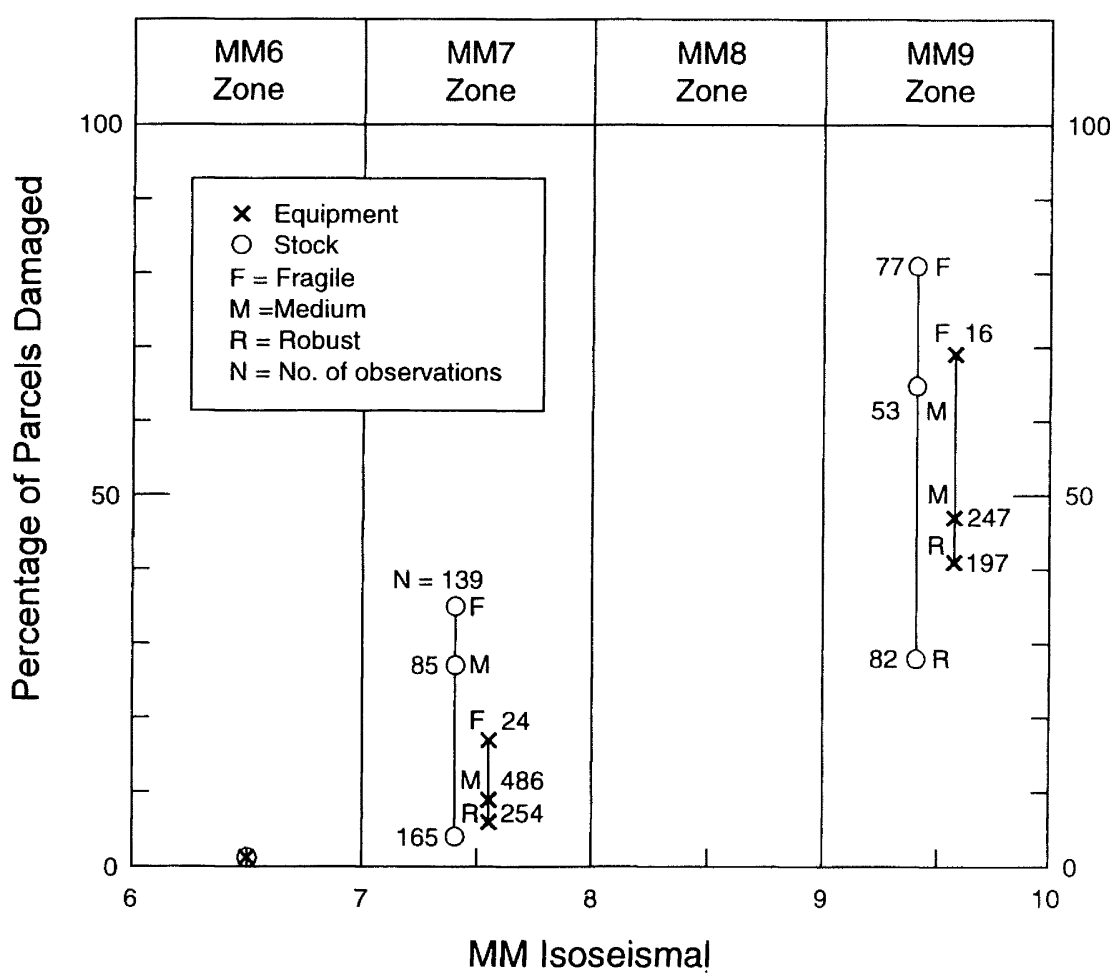

FIGURE 9 Percentage of parcels damaged, for the three vulnerability classes of equipment and stock, as a function of intensity in the 1987 Edgecumbe earthquake.

4 Considering classes of equipment according to Use (only), it was found that in the MM9 Zone $\mathrm{D}_{\mathrm{rm}}$ for shop equipment was about $50 \%$ greater than that for offices or industrial equipment (excluding Bay Milk). Given the precision of the estimates of the mean damage ratios, this difference is not statistically significant.

5 Considering stock according to classes of Use (only), it was found that $\mathrm{D}_{\mathrm{rm}}$ for shop stock was $70 \%$ greater that of industrial stock, with only modest overlap of the $95 \%$ confidence limits. Statistically, this difference is significant at the $5 \%$ level.

6 It has proved helpful for understanding the vulnerability of the population of equipment or stock to determine the proportional mix of items/parcels according to a reference classification of vulnerability, i.e. Robust, Medium or Fragile.

7 At MM9 the $\mathrm{D}_{\mathrm{rm}}$ values for Fragile equipment and stock are 14 and 15 times the $D_{\text {rm }}$ for their respective Robust classes. While this difference is large, the difference between the Fragile and Robust vulnerability classes at MM7 is much greater, the factors being 23 and 160 for equipment and stock respectively. This is consistent with the well known fact that the threshold intensity for damage to occur to fragile items is lower than that for robust items.

8 The large difference between $\mathrm{D}_{\mathrm{rm}}$ values of the Fragile and Robust classes at MM9 suggests that considerable reductions in damage levels could be achieved by design modifications to Fragile items, where "operator-friendly" protection systems can be found.
9 At MM9, the mean and distribution of damage ratios for equipment of Medium vulnerability were very similar to those for the associated post-code single storey commercial and industrial buildings.

10 For the larger data subsets, the damage ratios in the range $0<\mathrm{D}_{\mathrm{r}}<1$ for equipment and stock were found to fit well to the lognormal distribution.

11 Plots of $D_{r}$ against Replacement Value showed no simple relationship between these two variables. There was much more scatter of $D_{r}$ for equipment and stock than there was for the more homogeneous data of houses in Napier in 1931. In most data subsets the scatter is markedly greater at small Replacement Values.

12 Our various studies of damage ratios in this earthquake were feasible only as most of the data on insured damage costs came from a single source, namely the Earthquake and War Damage Commission (EQC). With the withdrawal of the EQC from the commercial market, it is imperative that insurance companies improve and co-ordinate their postearthquake data retrieval systems if further valuable insights are to be obtained into the earthquake resistance of New Zealand non-domestic property.

\section{ACKNOWLEDGEMENTS}

This study was funded by FRST principally under Contract No C05405. The authors are grateful to the New Zealand Earthquake and War Damage Commission for making available their claim files of the Edgecumbe earthquake. Claim data were 
also provided by the Insurance Council of New Zealand, Commercial Union Insurance, Farmers Mutual Group, New Zealand Insurance and Royal Insurance. We are also grateful to Peter Davenport and Donal Krouse for their helpful in-house reviews.

In addition many other people from various organisations helped by providing data in friendly co-operation. In particular our thanks go to the Bay of Plenty Regional Council, Kawerau District Council, Whakatane District Council, Bay Milk Co., Caxton Paper Mills, NZ Distillery, Tasman Forestry, Tasman Lumber Co., Tasman Pulp and Paper Co., Telecom NZ, Tunnicliffe Timber Co., Whakatane Board Mills, Valuation New Zealand, and a number of people involved with damaged schools.

\section{REFERENCES}

Dowrick. D.J. 1991. Damage costs for houses and farms as a function of intensity in the 1987 Edgecumbe earthquake, Earthquake Eng. Struct. Dynamics, 20:455-469.

Dowrick, D.J. and D.A. Rhoades. 1990. Damage ratios for domestic buildings in the 1987 Edgecumbe earthquake, Bulletin NZ National Society for Earthquake Eng., 23:137. 149.
Dowrick, D.J. and D.A. Rhoades. 1993. Damage costs for commercial and industrial property as a function of intensity in the 1987 Edgecumbe earthquake, Earthquake Eng. Struct. Dynamics, 22:869-884.

Dowrick, D.J. and D.A. Rhoades. Comparative vulnerability of different classes of buildings in the 1987 Edgecumbe, New Zealand, earthquake, (in preparation).

Dowrick, D.J., D.A. Rhoades, J. Babor and R.D. Beetham. 1995. Damage ratios and microzoning effects for houses in Napier in the magnitude 7.8 Hawke's Bay, New Zealand, earthquake of 1931, Bulletin New Zealand National Society for Earthquake Engineering, 25:134-145.

Lowry, M.A., S.C. Ede and J.S. Harris. 1989. Assessment of seismic intensities resulting from the 1987 Edgecumbe earthquake, New Zealand, and implications for modernising the intensity scale, NZ $J$ Geology and Geophysics, 32(1): 145-153. 